\title{
Does it mean anything to diagnose fibromyalgia (FM) in somebody with chronic widespread pain?
}

\author{
Luis Jose Catoggio ${ }^{1}$
}

Received: 12 May 2015 /Revised: 13 May 2015 / Accepted: 18 May 2015 / Published online: 29 May 2015

(C) International League of Associations for Rheumatology (ILAR) 2015

The paper in this volume by On et al. [1] raises the issue of whether there is a purpose in diagnosing fibromyalgia (FM) in patients with chronic widespread pain (CWP). They propose that, being FM at the more severe end of the spectrum of CWP, treatment is similar and whether to diagnose FM or not does not make a difference. Furthermore, since the update of FM criteria in 2010 which excludes the tender points, diagnosis has become more widespread and perhaps less specific. Diagnosis of FM with 2010 criteria includes many patients that would not fulfill 1990 criteria and excludes the concept of secondary fibromyalgia since patients with other conditions able to cause pain are excluded. Both the criteria, particularly the story behind both of them, have been well described by one of the main authors involved, Dr. Fred Wolfe [2, 3].

What a conundrum!

As a practicing rheumatologist who sees over one hundred patients a month in outpatient clinics, of which about a quarter are FM [4], I find diagnosing the condition useful. Furthermore, I also find it useful to differentiate between "primary" and "secondary" FM, considering the prevalence of FM in the musculoskeletal diseases (inflammatory or not) we treat. "Secondary", not in considering the inflammatory disease as a cause but to recognize that pain may be different and both conditions have to be approached in perhaps different ways.

This is an Editorial for http://dx.doi.org/10.1007/s10067-015-2975-1

Luis Jose Catoggio

luis.catoggio@hospitalitaliano.org.ar

1 Rheumatology Section, Hospital Italiano de Buenos Aires, Gascon 450, 1181 Buenos Aires, Argentina
But do clinicians, neurologists, rheumatologists, and psychiatrists who see the same patients with "presumed" FM or other conditions within the spectrum of chronic widespread pain call them differently and treat them in a similar way? Or are they really different situations? In which case, why should it be a similar treatment? Or, finally, should the treatments be different?

About three decades ago, I was told that fibromyalgia was what rheumatologists in the first half of the last century called fibrositis, and others "psychogenic rheumatism" [5]. Considering the links with anxiety, sleep disturbances, etc., the latter name has been useful to many of us in our approach to these patients. However, one thing about the links is the relationship between "psychological" factors and fibromyalgia and another is to regard them as causative agents of the condition [5].

When reading earlier literature, it is clear that fibrositis ended up being a misnomer, since the initial evidence of inflammation was not confirmed [6], and this is what most today call fibromyalgia. However, some authors in the late forties tried to differentiate between fibrositis and psychogenic rheumatism [5]. A lot of this information came from soldiers, both in the UK and the USA returning from the Second World War, with traumas arising from this event [5]. Yet both these terms, and many others, have been used since the late 1800 s to date as "equivalents" or variants of what we now call fibromyalgia as very elegantly reviewed by Inanici and Yunus in 2004 [6].

The term psychogenic, as meaning causative, has been an issue and recently addressed in another review [7] which augurs the demise of the term psychogenic rheumatism. However, as clearly stated in Inanici and Yunus' review [6], "this organic versus psychogenic polemic continues to persist today". Indeed, as late as 1978, Reynolds both described a series of patients with what he called psychogenic rheumatism [8] but also complained almost a decade later about the 
misinterpretation of references in relation to fibrositis (with data already clearly leading the way to the term fibromyalgia-tender points, sleep disturbances, etc.) and psychogenic rheumatism [9].

So what about approaches by other physicians ("nonrheumatologists") to similar problems? FM may account for up to a quarter of consultations in a general rheumatology practice, second only to osteoarthritis and up to $10 \%$ in family practice $[4,10]$, so the issue is no doubt important!

An approach to the so-called "somatoform" disorders (Diagnostic and Statistical Manual of Mental Disorders, 4th edition (DSM IV)) in family practice is interesting. Screening for these disorders using a validated questionnaire [11] shows that FM may easily qualify. The somatoform disorder classified as "pain disorder" is quite similar to "our" FM. And treatment includes exercise, cognitive behavioral therapy, anti depressants, etc. [11].

A very recent review addresses the changes between DSM IV and $\mathrm{V}$ regarding these disorders [12]. The new classification revolves around the effect the patients' feelings and thoughts have on their disability and use of health care services rather than on the medically unexplained symptoms (MUPS). At least in regard to the "pain disorder" subset similar to "our" FM recognized in DSM IV, this latter change does not appear very useful to me in "dissecting" FM patients in clinical practice. Rather, as with the 2010 FM criteria, it may allow for a wider spectrum of patients to be included.

A paper from general practitioner's (GP's) in Norway in a closed population showed that patients with MUPS accounted for $3 \%$ of consultations, $68 \%$ of complaints were musculoskeletal, and $57 \%$ asthenia and fatigue (where they "our FM"?). Interestingly, therapeutic approach was counseling by GP's in $64 \%$, and only $24 \%$ received some form of prescription (not described) [13].

Recent reviews in the Cochrane Library, both for pharmacologic and nonpharmacologic interventions for somatoform disorders, which probably include FM, show that quality of evidence is rather poor, and for most of these disorders ("mixed bag"), the use of antidepressants, both tricyclic and newer, were mildly beneficial, as were particularly the cognitive behavioral therapies as nonpharmacologic approaches. In both, reviewers stress that the quality of evidence is poor, and as far as nonpharmacologic therapies are concerned, they stress that the bias is towards patients who accepted some form of "psychological" therapy, and we have no information regarding those who did not $[14,15]$.

This variety of interpretations and approaches has led a USbased group to suggest an approach to FM by primary care providers [16] and the British Pain Society to develop a primary care approach for CWP including fibromyalgia [17].

Also recently, and because of all these difficulties, particularly in "sharpening" diagnosis, establishing treatment, and measuring results in follow-up, the OMERACT fibromyalgia working group has identified 12 domains including both clinical and biomarker data, to be used in trials, in order to assess these issues. The results allowed for four clusters of patients within FM with somewhat different degrees of involvement, particularly in physical and psychological factors, emphasizing that these patients are not a homogeneous group [18]. However, using this approach may give us more information regarding the nature of these conditions, all of which appear to have alterations of central pain mechanisms [19].

Very recently, published papers in this area go back and forth among the issues we have mentioned here, essentially interaction between physical and psychological issues [20] and different treatment modalities including onlinemonitored courses [21, 22].

So, in coming back to the start, I'll ask the following: Is it useful to diagnose FM in the context of chronic widespread pain or does it not make a difference? Undoubtedly, my opinion will be that of a rheumatologist. And, after having reviewed these papers discussed above, I still find it useful. And I find it useful to distinguish primary FM from that associated with other musculoskeletal diseases.

We rheumatologists have assumed the role of experts in "nonsurgical musculoskeletal diseases". This of course implies knowledge of anatomy which many of us may not have [23]. However, if we do (and I believe we should), we are then supposedly the best prepared to explore this (and thus tender points are useful to me), "circumscribe" our FM patients from others with widespread pain, and furthermore, we have the training to distinguish this pain from other inflammatory or noninflammatory musculoskeletal conditions which we often see. And this is critical in my point of view. This is not so for other subspecialties. However, primary care physicians are essential because of their knowledge of the patients under their care, their detailed personal and family history, etc. which it is clear is an essential part of these clinical pictures, FM or not, and they should be well trained to identify this and dissect primary from "associated" FM.

Finally, there is no doubt that a lot of the knowledge regarding fibromyalgia have arisen from rheumatology, so much so that the ACR criteria are used in the primary care approach, not only in the USA but also in Europe $[16,17]$. However, it would be useful for primary care providers (clinicians, family doctors, etc.), rheumatologists, neurologists, psychiatrists, etc. to get together and put into perspective the issues and possible definitions/overlaps/“limits" of CWP, FM, MUPS, and somatoform disorders.

If this was possible, we may be able to develop a better approach to these conditions for all of us involved in their care and for the benefit of the patients who should be our primary concern.

Disclosures None. 


\section{References}

1. On AY, Aykanat D, Atamas FC, Eyigor C, Kocanogullari H, Oksel F (2015) Is it necessary to strictly diagnose fibromyalgia syndrome in patients with chronic widespread pain? Clin Rheumatol. doi:10.1007/s10067-015-2975-1

2. Wolfe F (2010) New American College of Rheumatology criteria for fibromyalgia: a twenty-year journey. Arthritis Rheum 62(5): 583-584

3. Wolfe F, Claw D, Fitzcharles MA et al (2011) J Rheumatol 38(6): $113-122$

4. Bedran Z, Rosa J, Sabelli M et al (2010) Caracteristicas de pacientes atendidos en consultorios externos de reumatologia en un Hospital de Alta Complejidad. J Clin Rheumatol 16(3):S84

5. Boland E (1947) Psychogenic rheumatism: the musculoskeletal expression of psychoneurosis. Ann Rheum Dis 6:195-203

6. Inanici F, Yunus M (2004) History of fibromyalgia: past to present. Curr Pain Headache Rep 8:369-378

7. Pikoff $\mathrm{H}$ (2010) The psychological mislabeling of fibromyalgia. Int Musculoskelet Med 32:129-132

8. Reynolds MD (1978) Clinical diagnosis of psychogenic rheumatism. West J Med 128:285-290

9. Reynolds MD (1985) Psychogenic rheumatism and fibrositis. Arthritis Rheum 28:1435, letter

10. Goldenberg DM, Burckhardt C, Crofford L (2004) Management of fibromyalgia syndrome. JAMA 292:2388-2395

11. Oyama O, Paltoo C, Greengold J (2007) Somatoform disorders. Am Fam Physician 76:1333-1338

12. Alciati A, Atzeni F, Sgiarovello P, Sarzi-Puttini P (2014) Somatoform disorders and rheumatic diseases: from DSM-IV to DSM-V. Reumatismo 66:98-102

13. Aamland A, Malterud K, Werner E (2014) Patients with persistent medically unexplained physical symptoms: a descriptive study from Norwegian general practice. BMC Fam Pract 15:2-6
14. Kleinstauber M, Witthoft M, Stefanowski A, et al (2014) Pharmacological interventions for somatoform disorders in adults (review). Cochrane Collab 1-182. doi:10.1002/14651858. CD010628.pub2

15. Van Dessel N, den Boeft M, van der Wouden JC, et al (2014) Nonpharmacological interventions for somatoform disorders and medically unexplained physical symptoms (MUPSS) in adults (review). Cochrane Collab 1-120. doi:10.1002/14651858.CD011142.pub2

16. Arnold L, Claw DJ, Dunegan LJ et al (2012) A framework for fibromyalgia management for primary care providers. Mayo Clin Proc 87:488-496

17. Lee J, Price C, Baranowski AP (2014) Chronic widespread pain, including fibromyalgia: a pathway for care developed by the British Pain Society. Br J Anesth 112:16-24

18. Vincent A, Hoskin TA, Whipple MO et al (2014) OMERACTbased fibromyalgia symptom subgroups: an exploratory cluster analysis. Arthritis Res Ther 16:463

19. Philips K, Clauw DJ (2011) Central pain mechanisms in chronic pain states - maybe it is all in their head. Best Pract Res Clin Rheumatol 25:141-154

20. Talotta R, Atzeni F, Bazzichi L et al (2015) Algo-dysfunctional syndromes: a critical digest of the recent literature. Clin Exp Rheumatol 33(Supp 88):S102-S108

21. Leombruni P, Miniotti M, Colonna F et al (2015) A randomised controlled trial comparing duloxetine and acetyl L-carnitine in fibromyalgic patients: preliminary data. Clin Exp Rheumatol 33(Supp 88):S82-S85

22. Salaffi F, Ciapetti A, Gasparini S et al (2015) Web/Internet-based telemonitoring of a randomized controlled trial evaluating the timeintegrated effects of a 24-week multicomponent intervention on key health outcomes in patients with fibromyalgia. Clin Exp Rheumatol 33(supp 88):S93-S101

23. Alvarez-Nemegyei J (2012) Musculoskeletal clinical anatomy: a case-centered, cross examination-based teaching method. Rheumatol Clin 8(S2):1-2 